\title{
Performance Prediction Modelling for Flexible Pavement on Low Volume Roads Using Multiple Linear Regression Analysis
}

\author{
C. Makendran, ${ }^{1}$ R. Murugasan, ${ }^{1}$ and S. Velmurugan ${ }^{2}$ \\ ${ }^{1}$ Department of Civil Engineering, Anna University, Chennai 600025, India \\ ${ }^{2}$ Traffic Engineering and Safety Division, CSIR-Central Road Research Institute, New Delhi 110025, India \\ Correspondence should be addressed to C. Makendran; makendran2006@gmail.com
}

Received 15 March 2015; Revised 2 June 2015; Accepted 6 July 2015

Academic Editor: Wai Yuen Szeto

Copyright (c) 2015 C. Makendran et al. This is an open access article distributed under the Creative Commons Attribution License, which permits unrestricted use, distribution, and reproduction in any medium, provided the original work is properly cited.

\begin{abstract}
Prediction models for low volume village roads in India are developed to evaluate the progression of different types of distress such as roughness, cracking, and potholes. Even though the Government of India is investing huge quantum of money on road construction every year, poor control over the quality of road construction and its subsequent maintenance is leading to the faster road deterioration. In this regard, it is essential that scientific maintenance procedures are to be evolved on the basis of performance of low volume flexible pavements. Considering the above, an attempt has been made in this research endeavor to develop prediction models to understand the progression of roughness, cracking, and potholes in flexible pavements exposed to least or nil routine maintenance. Distress data were collected from the low volume rural roads covering about 173 stretches spread across Tamil Nadu state in India. Based on the above collected data, distress prediction models have been developed using multiple linear regression analysis. Further, the models have been validated using independent field data. It can be concluded that the models developed in this study can serve as useful tools for the practicing engineers maintaining flexible pavements on low volume roads.
\end{abstract}

\section{Introduction}

Road transportation sector plays a crucial role in accessing the growth of any country. India has very good road connectivity with nearly 4.4 million $\mathrm{km}$ length of roads [1]. Though enormous types of roads are available in India, low volume village roads connecting small villages with each other and also with other categories of roads play a vital role towards the economic growth of the country as such class of roads establishes direct linkages with agricultural and production sectors. Presently, the total length of low volume village roads in India is around 2,750,000 km [2]. Most of these roads are flexible pavements having poor pavement composition minimum required thickness of pavement layers as per IRC 37:2012 [3] and minimum acceptable quality of materials indicated in the Indian standard specification for road construction [4]. Even though the Government of India (GoI) is investing huge quantum of money on road construction every year, poor control over the quality of road construction and its subsequent maintenance is leading to the faster road deterioration. In this regard, it is essential that scientific maintenance procedures are to be evolved on the basis of performance of low volume flexible pavements. Even though, many scientific models are available for assessing the performance of flexible pavements, these cannot be applied to low volume roads providing connectivity primarily to the villages. The models developed elsewhere in Europe and North America for planning, design, construction, and maintenance of pavements $[5,6]$ for assessing the performance of flexible pavements are not transferable for Indian conditions as they are having the following basic impediments:

(i) Global models have a number of explanatory variables and the models require the development of adjustment factors to account for the local conditions.

(ii) In India, low volume village roads have very low traffic volume catering to less than 150 commercial vehicles per day (CVPD) coupled with inferior pavement composition. Therefore, the deployment of existing performance prediction models for low volume village roads in India by developing adjustment factors is a debatable decision. 
Moreover, due to paucity of funds, several low volume roads are not exposed to routine maintenance continuously for about four to six years. Therefore, an attempt has been made in this paper to develop distress prediction models indigenously for the flexible pavements covering village roads which cater to very less traffic volume (i.e.) less than 150 CVPD per day as such models can be directly applied without the need to evolve any adjustment factor.

\section{Literature Review}

The literature related to models developed pertaining to the performance prediction of the flexible pavement has been reviewed and the observations are summarized in Table 1.

Based on the review of the above literature, it is evident that the factors such as traffic loading, age, pavement strength, and environmental conditions are generally influencing the behavior of flexible pavements and, therefore, the indigenous models have to be developed encompassing the effect of local conditions. The HDM-IV models developed by World Bank involve large number of variables which require calibration for the local conditions. As such, the models available for the low volume flexible pavements catering to traffic less than 150 CVPD are very limited.

\section{Objectives of the Study}

Based on the above reviewed literature and ground requirements, the objectives of this study have been evolved as follows:

(i) To develop performance prediction models accounting for the distress such as roughness, cracking, and potholes encompassing the flexible pavements in village roads.

(ii) To develop most versatile model to enable the field engineers to use it without any difficulty.

\section{Study Methodology}

The entire research work has been divided into the following steps. (i) The locations of test sections on in-service pavements were identified with different age groups. (ii) Pavement distress such as roughness, cracking, and potholes was measured. (iii) The strength of pavement sections was calculated in terms of modified structural number (MSN) which is a function of subgrade CBR and pavement composition. The pavement composition details for the test sections were obtained from the road agencies and the same was confirmed while making pits for CBR tests. (iv) Rainfall particulars for the study area were collected from metrological department of India. (v) Pavement performance prediction models were developed by multiple linear regression analysis using SPSS software. (vi) Validation analysis was carried out for all the three models.

4.1. Identification of Test Sections. The district of Thiruvallur in the state of Tamil Nadu in India has been chosen as the study area. A total 173 test sections spanning a length of $200 \mathrm{~m}$ each were identified in consultation with Rural Road and Panjayat Raj Department Officials of the State. Care was exercised to collect test sections falling under varying levels of distress and roughness for the study purpose. The following criteria were adopted for the identification of test sections:

(i) Selection of village roads with low traffic volume (less than 150 CVPD).

(ii) Sections on straight reaches and plain terrains.

(iii) Sections without cross roads, cross drainage works, and habitations.

(iv) Sections with uniformity in longitudinal and transverse directions with regard to crust composition, subgrade, drainage, and surface conditions to the possible extent.

4.2. Distress Measurements. The distress such as roughness, cracking, and potholes was measured in all the 173 test sections as described below.

4.2.1. Roughness. The roughness measurements were taken with the towed Fifth Wheel Bump Indicator [10], which is one of the standard devices for measuring roughness in India. The output of this device is in $\mathrm{mm} / \mathrm{km}$ or $\mathrm{m} / \mathrm{km}$ [16]. The observations were taken on the outer wheel path in both directions, at a distance of $0.6 \mathrm{~m}$ from the edges of the pavement, till three nearly consistent readings were obtained and the average of these three readings was taken as the roughness value [16].

The following precautions were taken during measurements:

(a) The speed of the vehicle was maintained uniform to the possible extent around $30 \mathrm{~km} / \mathrm{h}$, that is, $\pm 2 \mathrm{~km} / \mathrm{h}$. This speed was attained before reaching the section and attempt was made to maintain the same speed for some distance before reaching the section.

(b) Considering the need to maintain consistency during data collection phase, the same bump integrator unit was used on all the test sections during different series of observations.

(c) For nonexperimental running, the unit was run on towing wheel.

The towed fifth wheel bump integrator was periodically calibrated, before the measurement with a standard bump integrator which was used for calibration purpose only.

4.2.2. Cracking. For measurements, all types of cracks were combined together and the affected area was marked in the form of square or rectangle. The length and breadth of distressed areas were measured by a tape. In case of single longitudinal and transverse cracks, the crack length was measured and effective width was taken as $300 \mathrm{~mm}$. In each segment, total area of cracking was calculated and entered as a percentage of segment area [10]. 


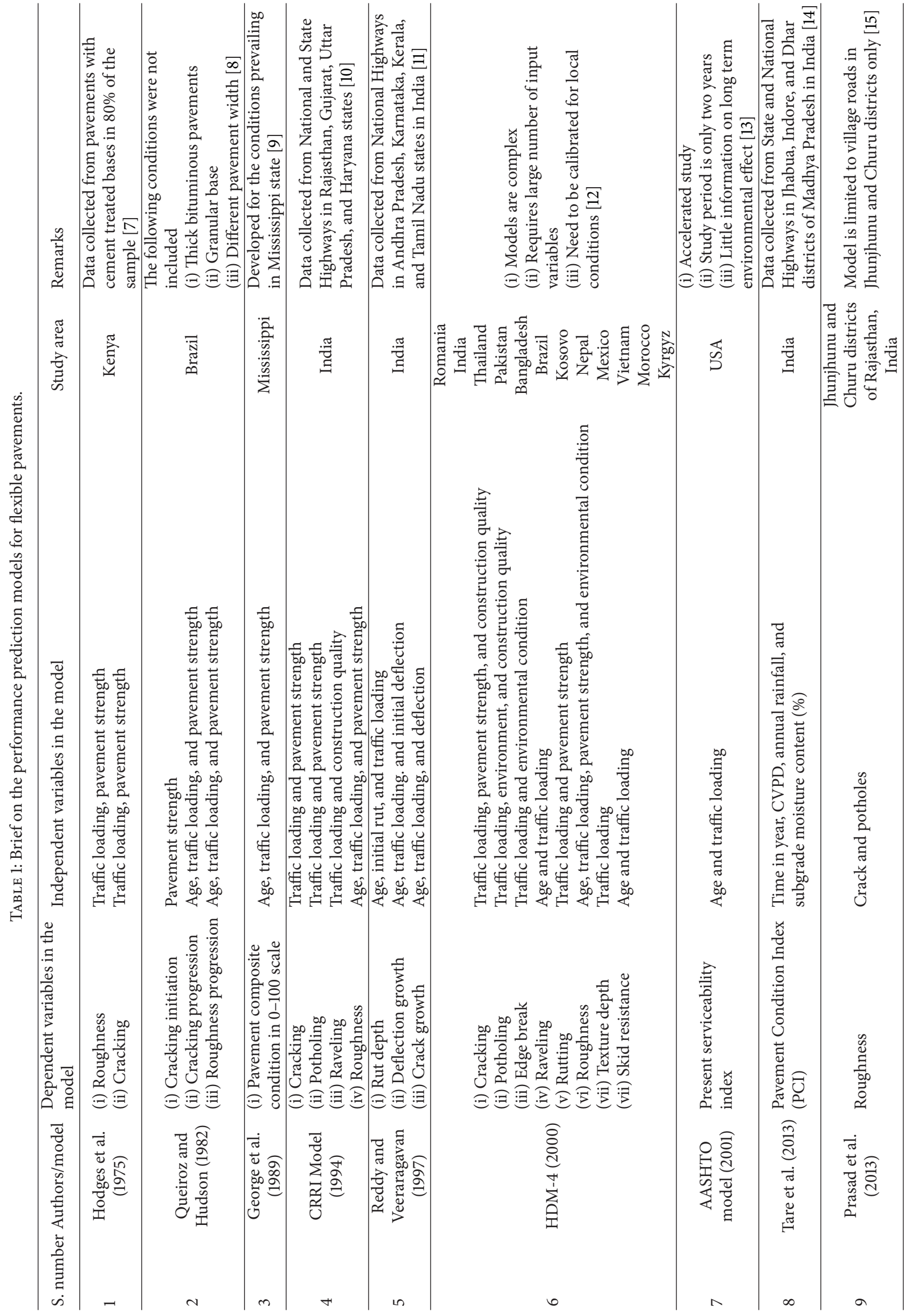


TABLE 2: Range of data used for model development and validation.

\begin{tabular}{|c|c|c|c|c|c|}
\hline Description & Notation & Unit & Minimum & Maximum & Mean \\
\hline Commercial vehicle per day & CVPD & number & 2 & 9 & 5.5 \\
\hline Pavement age since last renewal & AGE & Years & 0 & 10.5 & 5.25 \\
\hline Modified structural number & MSN & - & 0.91 & 2.78 & 1.845 \\
\hline Roughness value & ROU & $\mathrm{m} / \mathrm{km}$ & 3 & 9 & 6 \\
\hline Cracking area & CR & $\%$ & 0 & 17 & 8.5 \\
\hline Pothole area & $\mathrm{PH}$ & $\%$ & 0 & 27 & 13.5 \\
\hline Annual rainfall & $\mathrm{RN}$ & $\mathrm{mm}$ & 695 & 2139 & 1417 \\
\hline
\end{tabular}

4.2.3. Potholes. For measurements, potholes were combined together and the affected area was marked in the form of square or rectangle. The length and breadth of distressed areas were measured by a tape. In each segment, total area of potholes was calculated and entered as a percentage of segment area [10].

4.2.4. Traffic Volume Survey. The traffic surveys were conducted for seven consecutive days round the clock, by engaging adequate number of enumerators. From the traffic survey data, the number of commercial vehicles per day (CVPD) was calculated for each section and the same has been utilized for model development [3].

4.3. Pavement Strength. Pavement strength in this study is measured in terms of modified structural number (MSN). The concept of structural number (SN), a pavement strength indicator, was originally developed during the AASHTO Test [5]. The relationship used to obtain the structural number of a pavement is given below:

$$
\begin{aligned}
\mathrm{SN} & =a_{1} \times t_{1}+a_{2} \times t_{2}+a_{3} \times t_{3}+\cdots+a_{n} \times t_{n} \\
& =\sum_{i=1}^{n} a_{n} \times t_{n},
\end{aligned}
$$

where $a_{1}, a_{2}, a_{3}, \ldots, a_{n}$, are the strength coefficients of materials used in different pavement layers and $t_{1}, t_{2}, t_{3}, \ldots, t_{n}$ are the corresponding thickness in inches.

The strength coefficients suggested by Central Road Research Institute (CRRI), New Delhi, for Indian conditions for different materials are used in this study [10].

The structural number (SN) thus obtained is modified to account for the subgrade strength using the following equation [5]:

$$
\begin{aligned}
\mathrm{MSN}= & \mathrm{SN}+3.51\left(\log _{10} \mathrm{CBR}\right)-0.85\left(\log _{10} \mathrm{CBR}\right)^{2} \\
& -1.43
\end{aligned}
$$

where MSN is the modified structural number, $\mathrm{SN}$ is the structural number, CBR is the California Bearing Ratio of subgrade soil.

4.4. Rainfall Particulars. Rainfall particulars for the test sections were collected from Meteorological Department of India and utilized.
4.5. Development of Performance Models. The distress measurements made on all the 173 test sections during the course of the study were analyzed to obtain the input parameters for the development of models. The dependent variables considered in this study are (i) roughness, (ii) cracks, and (iii) potholes.

The independent variables considered in this study are traffic volume in terms of number of commercial vehicles per day (CVPD), pavement strength in terms of MSN, and age since last renewal of pavement surface and cumulative rainfall. Since the environmental conditions are almost the same throughout the study area, expect some variations in rainfall, rainfall data was also considered in this study as one of the independent variables. Out of the 173 test sections, data collected from 120 test sections were kept as "in-sample" data for model development and the remaining were designated as "out-of -sample" data for model validation. The in-sample data and out of sample data were obtained by sorting the data randomly. The range of data used for the model development and validation is given in Table 2 .

\section{Roughness Prediction Model}

In this model, roughness value was taken as the dependent variable and the measured pavement parameters, namely, AGE, MSN, CVPD, and RN, were considered as independent variables. Though the independent variable " $\mathrm{RN}$ " did not exhibit any significance, good correlation exists between roughness and the other three independent variables. The significance of independent variables in descending order was observed to be AGE, MSN, and CVPD.

The best model obtained using multiple linear regression analysis is as follows:

$$
\begin{aligned}
& \mathrm{ROU}=4.509+0.513 \mathrm{AGE}-1.004 \mathrm{MSN} \\
& +0.121 \mathrm{CVPD} \\
& \quad\left(R^{2}=0.896, \mathrm{SE}=0.77, N=120\right) .
\end{aligned}
$$

In the above model, roughness increases with increase in CVPD and AGE, as they appear with positive coefficients. On the contrary, roughness decreases with increase in MSN, as it appears with negative coefficient. The negative sign indicates that the stronger the pavement, the lesser the potential for surface unevenness.

In order to explain the robustness of the model, a plot is made between observed roughness values of the out of 


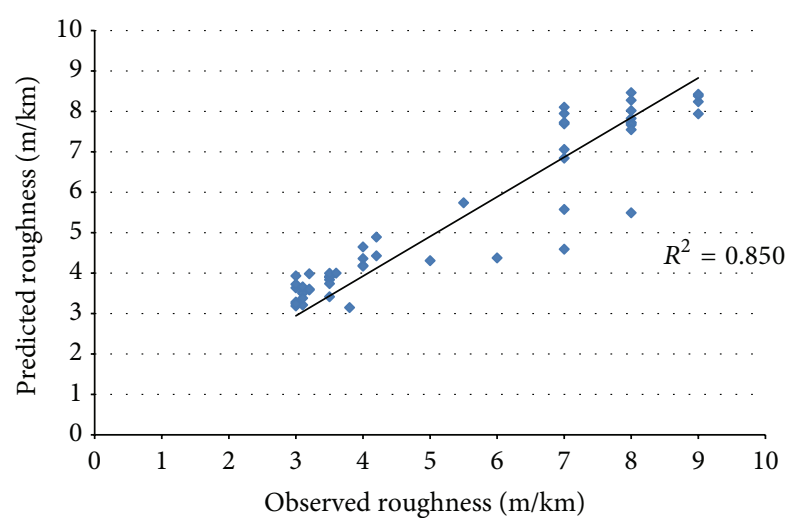

FIGURE 1: Comparison between predicted and observed roughness values based on the out of sample data.

sample data and predicted roughness values from the model as shown in Figure 1. The alignment of plotted points along the line of equality indicates the robustness of the model.

\section{Crack Prediction Model}

In this model, measured crack value was taken as the dependent variable and the measured pavement parameters, namely, AGE, MSN, and CVPD, were considered as independent variables. Though variable independent "RN" did not exhibit any significance, good correlation exists between crack and the other three independent variables. The significance of independent variables in descending order was observed to be AGE, MSN, and CVPD.

The best model obtained using multiple linear regression analysis is as follows:

$$
\begin{array}{r}
\mathrm{CR}=2.114+1.191 \mathrm{AGE}-1.783 \mathrm{MSN}+0.260 \mathrm{CVPD} \\
\left(R^{2}=0.916, N=120\right) .
\end{array}
$$

In the above model, cracking increases with increase in CVPD and AGE, as they appear with positive coefficients. On the contrary, cracking decreases with increase in MSN, as it appears with negative coefficient. The negative sign indicates that the stronger the pavement, the lesser the potential for cracking. In order to explain the robustness of the model, a plot is made between observed cracking values of the out of sample data and predicted cracking values from the model as shown in Figure 2. The alignment of plotted points along the line of equality indicates the robustness of the model.

\section{Development of Pothole Model}

In this model, measured crack value was taken as the dependent variable and the measured pavement parameters, namely, AGE, MSN, and CVPD, were considered as independent variables. In the prediction of potholes model, the independent variable "RAIN" did not exhibit any significance, good correlation exists between potholes and the other three independent variables. The significance of independent

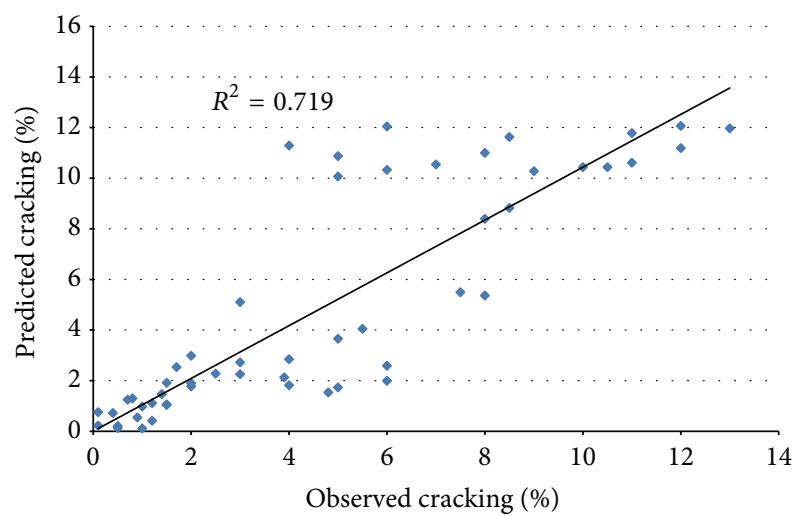

FIGURE 2: Comparison between predicted and observed cracking values based on the out of sample data.

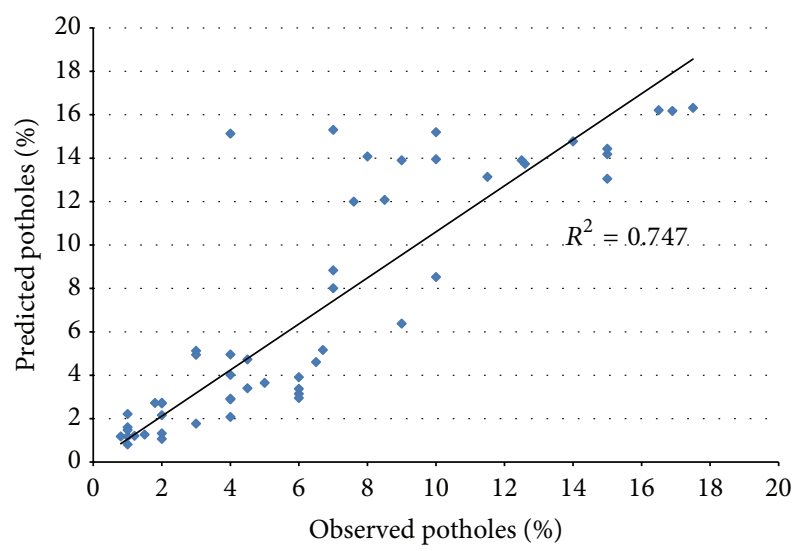

FIGURE 3: Comparison between predicted and observed pothole values based on the out of sample data.

variables in descending order was observed to be AGE, MSN, and CVPD.

The best model obtained using multiple linear regression analysis is as follows:

$$
\begin{array}{r}
\mathrm{PH}=3.922+1.403 \mathrm{AGE}-2.819 \mathrm{MSN}+0.592 \mathrm{CVPD} \\
\left(R^{2}=0.878, N=120\right) .
\end{array}
$$

In the above model, pothole increases with increases in CVPD and AGE, as they appear with positive coefficients. On the contrary, pothole decreases with increase in MSN, as it appears with negative coefficient. The negative sign indicates that the stronger the pavement, the lesser the potential for formation of the potholes.

In order to explain the robustness of the model, a plot is made between the observed pothole values of the out of sample data and predicted pothole as shown in Figure 3. The alignment of plotted points along the line of equality indicates the robustness of the model. 
TABLE 3: Statistics of the performance prediction models.

\begin{tabular}{|c|c|c|c|c|c|c|}
\hline S. number & Dependent variable & Independent variable & Coefficients & Student's $t$ & $p$ value & VIF \\
\hline \multirow{3}{*}{1} & \multirow{3}{*}{ Roughness } & (i) Age & 0.513 & 22.085 & $2.308 \times 10^{-43}$ & 1.600 \\
\hline & & (ii) MSN & -1.004 & -3.978 & 0.000 & 1.187 \\
\hline & & (iii) CVPD & 0.121 & 2.331 & 0.021 & 1.444 \\
\hline \multirow{3}{*}{2} & \multirow{3}{*}{ Cracking } & (i) Age & 1.191 & 25.352 & $3.961 \times 10^{-49}$ & 1.600 \\
\hline & & (ii) MSN & -1.783 & -3.489 & 0.000 & 1.187 \\
\hline & & (iii) CVPD & 0.260 & 2.482 & 0.015 & 1.444 \\
\hline \multirow{3}{*}{3} & \multirow{3}{*}{ Potholes } & (i) Age & 1.403 & 19.334 & $4.401 \times 10^{-38}$ & 1.600 \\
\hline & & (ii) MSN & -2.819 & -3.571 & 0.000 & 1.187 \\
\hline & & (iii) CVPD & 0.592 & 3.652 & 0.000 & 1.444 \\
\hline
\end{tabular}

\section{Statistical Validity of the Models}

To check the statistical validity of the models and checking the significance of the variables, well-known "Student's $t$ " values and " $p$ values" for each of the independent variables considered in the models are calculated and presented in Table 3.

The acceptable "Student's $t$ " statistic value for 95\% confidence level is 1.645. It has been observed from Table 3 that "Student's $t$ " values estimated for all the distress parameters are greater than 1.645, which implies that the dependent variable follows a normal distribution with a constant variance across observations. These values represent the confidence of the model parameters at $95 \%$ confidence interval. It has been observed from Table 3 that the " $p$ values" for all distress parameters are less than 0.05 ; hence all the variables included in the models are acceptable and found to be significant for model development. Regression statistics and the results of ANOVA are also presented in Tables 4 and 5. From Table 4 it has been observed that the value of "Multiple $R$ " is $0.946,0.956$, and 0.937 for roughness, cracking, and potholes, respectively. It can be also observed from Table 4 that the Standard Expected Error between the observed and predicted roughness, cracking, and pothole values is $0.77 \mathrm{~m} / \mathrm{km}$, $1.56 \%$, and $2.41 \%$, respectively. Further, it can be inferred from Table 5 that the values of "Significance $F$ " are less than 0.05 for all the three models signifying the fact that the developed models are significant. The relevance for each of the independent variables considered in this study was further corroborated by the collinearity statistics presented in Table 3. It is evident from Table 3 that the Variance Inflation Factor (VIF) is always greater than " 1 " and also the strength of the independent variables was established due to the fact that VIF values are ranging between " 1 " and " 2 " thereby nullifying the presence of multicollinearity between the independent variables.

\section{Conclusions}

(i) The models, developed in this study, are thoroughly evaluated for their effectiveness by validation process and thereafter tested to understand their prediction capability. Comparison of the predicted values with
TABLE 4: Regression statistics of the developed models.

\begin{tabular}{lccc}
\hline Regression statistics & $\begin{array}{c}\text { Roughness } \\
\text { model }\end{array}$ & $\begin{array}{c}\text { Cracking } \\
\text { model }\end{array}$ & $\begin{array}{c}\text { Pothole } \\
\text { model }\end{array}$ \\
\hline Multiple $R$ & 0.946 & 0.957 & 0.937 \\
$R$ square & 0.896 & 0.916 & 0.878 \\
Adjusted $R$ square & 0.893 & 0.913 & 0.875 \\
Standard error & 0.773 & 1.564 & 2.417 \\
Observations & 120 & 120 & 120 \\
\hline
\end{tabular}

TABLE 5: ANOVA results of the models.

\begin{tabular}{lccccc}
\hline & df & SS & MS & $F$ & Significance $F$ \\
\hline \multicolumn{5}{c}{ (i) Roughness model } \\
Regression & 3 & 595.067 & 198.356 & 331.962 & $9.562 E-57$ \\
Residual & 116 & 69.313 & 0.598 & & \\
Total & 119 & 664.371 & & & \\
\hline
\end{tabular}

\begin{tabular}{lccccc}
\hline \multicolumn{5}{c}{ (ii) Cracking model } \\
Regression & 3 & 3081.413 & 1027.138 & 419.902 & $4.190 E-62$ \\
Residual & 116 & 283.752 & 2.446 & & \\
Total & 119 & 3365.165 & & & \\
\hline \multicolumn{5}{c}{ (iii) Pothole model } \\
Regression & 3 & 4878.311 & 1626.106 & 278.388 & $8.109 E-53$ \\
Residual & 116 & 677.574 & 5.841 & & \\
Total & 119 & 5555.893 & & & \\
\hline
\end{tabular}

actual values (out of sample data) demonstrates their accuracy.

(ii) The significance of independent variables in descending order in the models are found to be age, modified structural number (MSN), and traffic.

(iii) The rainfall factor is found to be insignificant factor as the test sections in this study were not subjected to any conditions of inundation.

(iv) The models developed in this study can be used as an effective tool in maintenance management of flexible pavements for low volume village roads. 


\section{Suggestion for Further Study}

The strength coefficients of the pavement layers may change with time due to the effects of repetitions of loading and environmental conditions. This aspect is not accounted for in this study considering the volume of work. The changes in strength coefficients in pavement layers for the materials used for the construction of low volume village roads in India may be taken up as a further study.

\section{Conflict of Interests}

The authors declare that there is no conflict of interests regarding the publication of this paper.

\section{References}

[1] G. Shailendra and A. Veeraragavan, "Quantification of benefits of improved pavement performance due to good drainage," Journal of the Indian Roads Congress, vol. 71, no. 1, pp. 77-99, 2010, Paper No. 558.

[2] P. Agarwal and A. P. Singh, "Some strategies for sustainable maintenance of rural roads in india," International Journal of Advanced Engineering Technology, vol. 1, no. 3, pp. 304-311, 2010.

[3] Indian Roads Congress, IRC: 37-2012, Guidelines for the Design of Flexible Pavements, Indian Roads Congress, New Delhi, India, 2012.

[4] MORTH, Specifications for Road and Bridge Work, Ministry of Road Transport and Highways, New Delhi, India, 2001.

[5] AASHO, "The AASHO road test report," Pavement Research, National Academy of Sciences, National Research Council, Highway Research Board, Washington, DC, USA, 1962.

[6] Transport Research, Long Term Performance of Road Pavements, European Cooperation in the Field of Scientific and Technical Research, Luxemburg, Belgium, 1997.

[7] J. W. Hodges, J. Rolt, and T. E. Jones, "The Kenya road transport cost study: research on road deterioration," Transport and Research Laboratory Report 673, Transport and Research Laboratory, 1975.

[8] C. A. V. Queiroz and W. R. Hudson, "Improved pavement performance relationship in brazil," in Proceedings of the 5th International Conference on the Structural Design of Asphalt Pavements, vol. 1, pp. 500-510, The University of Michigan, Ann Arbor, Mich, USA, 1982.

[9] K. P. George, A. S. Rajagopal, and L. K. Lim, "Models predicting pavement deterioration," Transportation Research Record, no. 1215, pp. 1-7, 1989.

[10] CRRI, Pavement Performance Study on Existing Sections, Final Report, vol. 1 \& 2, Central Road Research Institute, Government of India, New Delhi, India, 1994.

[11] B. B. Reddy and A. Veeraragavan, "Structural performance of inservice flexible pavements," Journal of Transportation Engineering, vol. 123, no. 2, pp. 156-167, 1997.

[12] C. R. Bennet and W. D. O. Paterson, HDM-4 Highway Development and Management, vol. 5 of A Guide to Calibration and Adaptation, International Study of Highway Development and Management Tool, The World Road Association, Paris, France, 2000.

[13] AASHTO, Pavement Management Guide, American Association of State Highway and Transportation Officials, 2001.
[14] V. Tare, H. S. Goliya, A. Bhatore, and K. Meshram, "Pavement deterioration modelling for low volume roads," Indian Highways, vol. 73-74, no. 590, pp. 67-81, 2013.

[15] J. R. Prasad, S. Kanuganti, P. N. Bhanegaonkar, A. K. Sarkar, and S. Arkatkar, "Development of relationship between roughness (IRI) and visible surface distresses: a study on pmgsy roads," Procedia: Social and Behavioral Sciences, vol. 104, pp. 322-331, 2013.

[16] MORTH, Guidelines for Maintenance Management of Primary, Secondary and Urban Roads, Ministry of Road Transport \& Highways, New Delhi, India, 2004. 


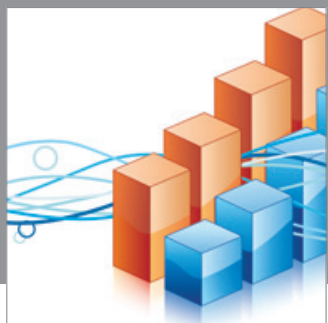

Advances in

Operations Research

mansans

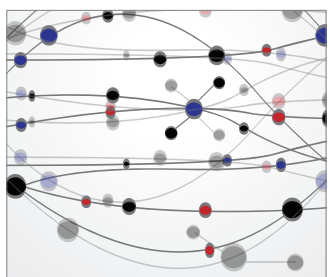

The Scientific World Journal
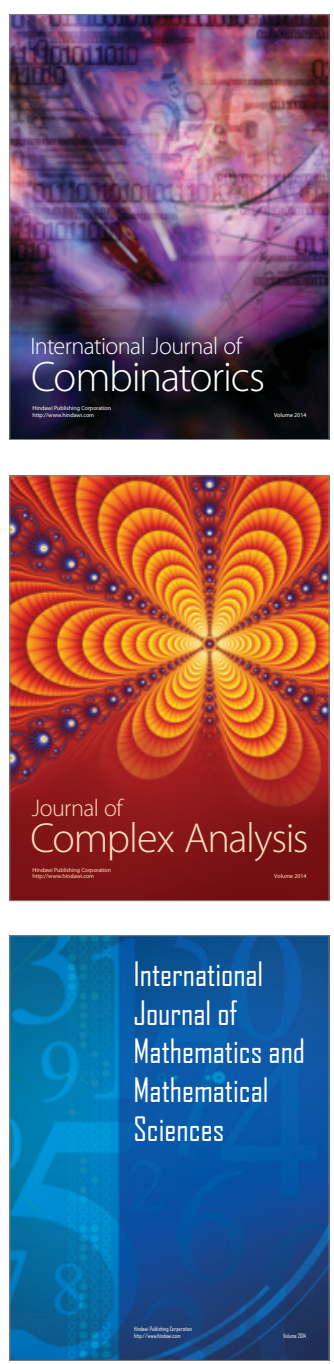
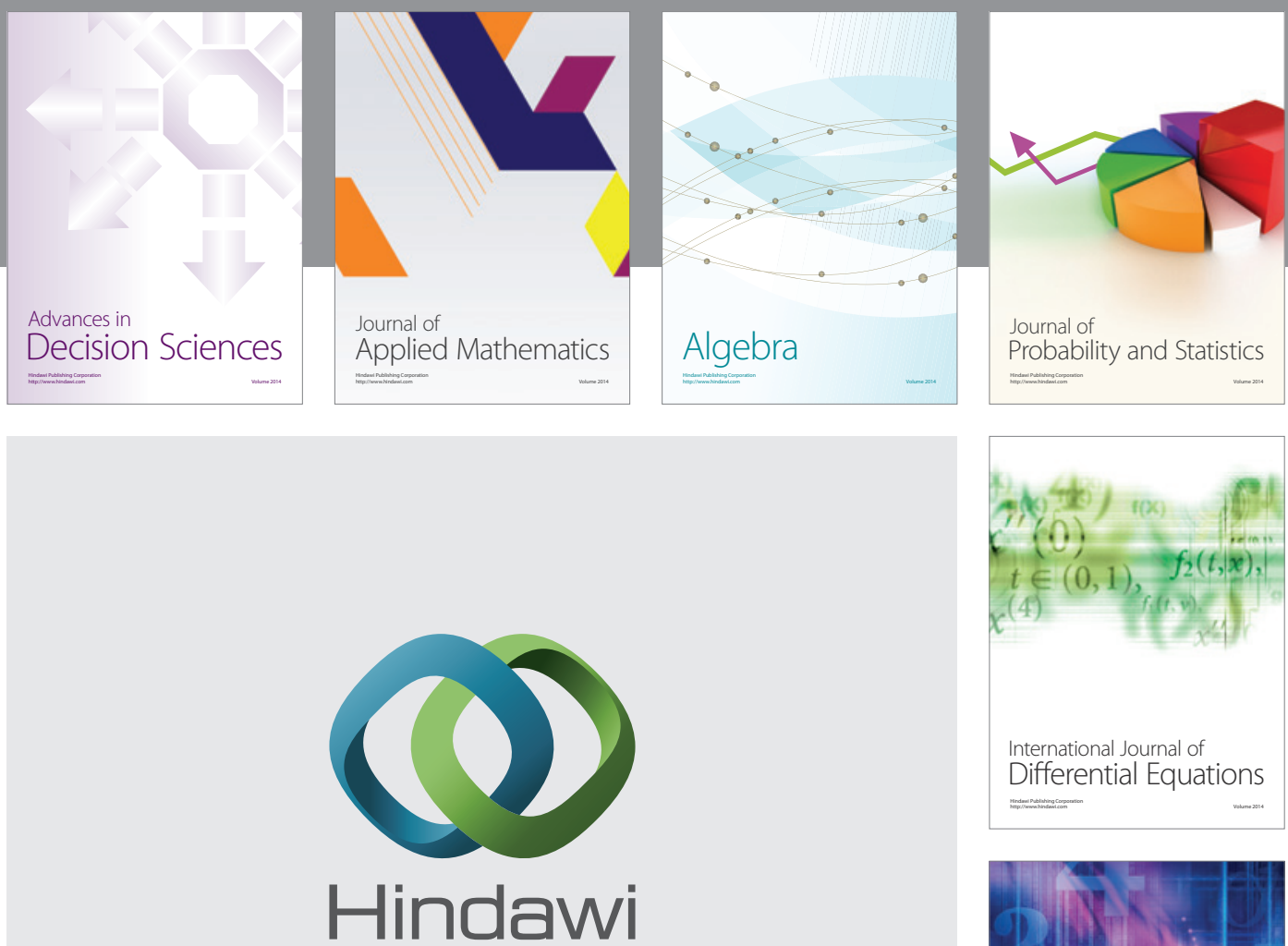

Submit your manuscripts at http://www.hindawi.com


Journal of

Function Spaces

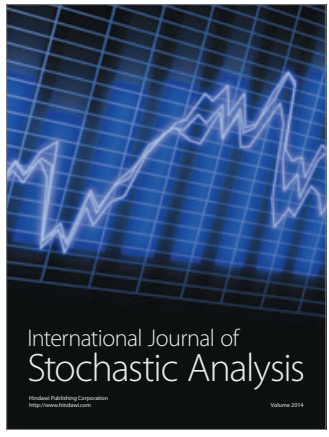

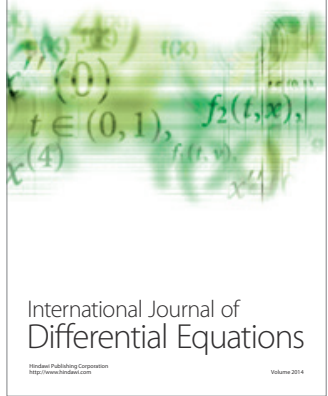
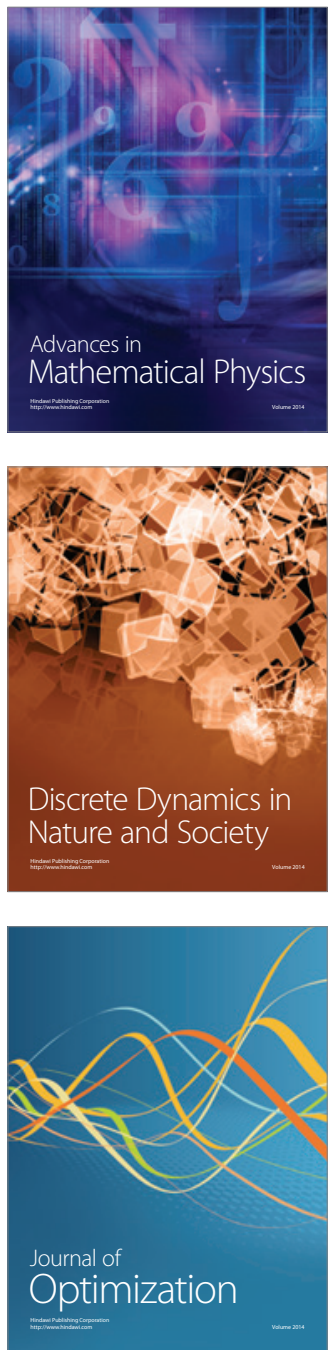